\title{
European food aid as a tool for relief and development in Sub-Saharan Africa
}

By E. J. Clay, Institute of Development Studies, University of Sussex, Brighton $B N I$ gRE

\section{Summarized proposals}

As the African food emergency wanes, there is an urgent need to examine the future role for European Community (EC) food aid in Africa. The provision of emergency aid and support for development raise different issues. However, timely and appropriate responses to emergencies minimize the disruptive effects of food crisis whereas late and then probably excessive responses hamper rehabilitation and involve high risks of disincentives to local agriculture. Consequently, the EC needs to improve its capacity to respond rapidly and appropriately to food emergencies. The establishment of an initially small operational reserve of commodities under the management of the EC Commission is seen as a necessary element of an effective emergency programme. It would provide support through international channels, such as the International Emergency Food Reserve supporting the actions of non-governmental organizations (NGOs), and direct aid to affected countries. The problems to be overcome in establishing such reserves are not so much significant budgetary cost as budgetary practice and overcentralization of responsibility at a political level. These obstacles can be surmounted, if in the wake of recent experiences there is a genuine political commitment to create an effective emergency response capacity within the EC.

The greater part of food aid is provided for development and sold in Third World countries. This aid provides balance of payments relief and budgetary support. The historical record for food aid is inconclusive as to the effects on development generally and on agriculture in recipient countries. The implication is that food aid offers opportunities, but realization of these depends on constructive policies on the part of both recipients and donors. Africa poses a particularly difficult problem because of the limited scope for industrial growth, the type of commodities available are not the basic staples of poor and rural consumers, and problems of management. The instability of African food production intensifies further the pressure on limited management capacity spread thinly across so many countries. More careful regard for the long-term economic consequences of developmental aid is required. This makes it imperative that the EC sustains its commitment to food strategies, closely co-ordinating its aid with that of other food donors as part of a long-term relation with recipient governments. A serious problem on the donor side has been a 'lack of staying power' as agencies pursue topical initiatives. There has also been a. lack of flexibility particularly in 
responding to the rapidly changing situation in Africa. Currently there is an urgent need to increase considerably support for 'triangular transactions' financing the exports of African countries temporarily in surplus, by purchases or swap agreements.

\section{The spectre and the feast}

The spectacle of food surpluses in Europe side by side with the spectre of famine in Africa has led many people to pose the question: how can we use these surpluses to combat the immediate problems of hunger in Africa? Some go on to ask: how can we facilitate the recovery from crisis and foster long-term self-reliant development? These are not new questions, only the context has changed.

These questions were posed in an almost identical form in North America at the end of the Second World War when the problem of hunger and reconstruction in Western Europe was immediate and visible in the newsreels. The outcome of this debate was the Marshall Plan. By the early 1950s European recovery was in full swing. The food deficits were shrinking and could be financed from export earnings. The United States Congress, faced with the political reality of continuing agricultural surpluses, laid the legislative basis, the so-called Public Law 480 of 1954, for a food aid programme directed towards developing countries. The problems of hunger and lack of resources to sustain development were then primarily questions about South and East Asia and much of Latin America. Africa was still effectively under European colonial rule. Subsequently, we have had 30 years' continuous experience of food aid on a historically unprecedented scale, both for humanitarian and developmental purposes. But self-interest of the donor in terms of managing short-run agricultural surpluses and the longer-term development of markets for agricultural exports, as well as foreign policy goals, have been accepted as equally legitimate. These trade policy goals were made explicit in the original legislation and have been recently reiterated in the Food Security Act of 1985 . If agricultural policy concerns have been less explicit in the public definition of European food aid, the historical lesson is that it should be regarded at least as potentially a constraint on the scope, scale and flexibility of a food aid programme. For example, current tendering procedures for food aid reflect agricultural policy rather than food aid management concerns. If only the latter were at issue, it would be done differently.

Up to about 1970 the US PL 480 programme, accounting for $80-90 \%$ of food aid commodities, effectively was food aid. But since the Food Aid Convention of 1967 , negotiated as part of the International Grains Agreement, the EC has become progressively involved in providing food aid directly to governments, and through voluntary agencies (NGOs) and international organizations, particularly the World Food Programme. European food aid first became a significant resource during the earlier food crisis of 1972-74. This aid is managed both directly by the EC Commission (Community Action) and by member states (National Action). Taken together, Community and National Actions have represented between one-quarter and one-third of all food aid in recent years from the international and Western 
national agencies. The United States has provided around $50 \%$ of total food aid. The other important programmes are those of Canada, Australia, Japan and the Nordic countries as a group.

The food problems of individual countries, although these have important regional and sectoral dimensions, are in a real sense national and indivisible. They do not readily lend themselves to segmentation as a series of projects or programmes that can be funded separately by a large number of donors. Nevertheless, there has been only limited progress towards co-ordinating food aid flows, except in the special circumstances of a few countries (e.g. the original Mali food security agreement) or specific emergencies (Kampuchean refugees). As recent experiences in Ethiopia, Mali and the Sudan have shown there is a desperate need for more consistent and integrated responses on the part of all donors.

There is not one EC programme, but in effect one large and ten smaller programmes as well as all the autonomous NGO activities supported by the EC and EC member states. Looked at from a European perspective, the management of surpluses is a common economic problem. However, cereals food aid from the EC has come to be split on a $55 \%$ Community Action- $45 \%$ National Action basis in recent years, with dairy and other products largely being financed through Community Action. Is there scope for a common response? Yes, but are there serious possibilities of a common response? The way in which the EC has handled both the financing and management of food aid has exacerbated rather than simplified the problems of co-ordinating food aid programming from the donor side. Almost half of the 'Community Action' cereals food aid represents expenditure which is accounted to individual national aid budgets and represents resources under the control of national aid agencies. So long as 'Community Action' food aid expenditure is accounted to the aid budgets by some member states, the aid ministries will naturally wish to retain some influence over these resources. There are also national agricultural interests not far below the surface of the problem. What are the possibilities for constructive action on making food aid a more effective resource for development?

\section{Food aid involves financial and human resources as well as surplus food}

In focusing on the opportunity to respond to the problem of hunger and poverty in Africa provided by surplus commodities within the EC, it is important to recognize that there are substantial associated costs involved in effecting these transfers. Where grain costs US $\$ 150 /$ tonne, the full cost of delivering it can rise to $\$ 600-700 /$ tonne if air transport is used in an emergency situation. The cost of food aid includes processing, packaging, transport and also administration. As a rule of thumb, these are, at a minimum, likely to represent an addition of $50 \%$ to the commodity costs even in the most favourable circumstances, i.e. bulk cereal shipments to a coastal destination in sub-Saharan Africa. These considerations of associated non-commodity costs are particularly important when taking a view of the appropriateness of moving surplus commodities from Europe to land-locked destinations in sub-Saharan Africa. For example, the acquisition of commodities 
within the region may be more cost-effective than shipping food from Europe. At the moment, the cost of purchasing maize in Zimbabwe to support activities in Botswana, Zambia and some parts of Mozambique and southern Zaire could be below the shipping costs from Europe. Similarly, it may be more appropriate to acquire grain in Niger for use in that country or other parts of the Sahel region than to import from Europe. Such narrow questions of cost-effectiveness are clearly dependent on a changing commodity supply situation. Cost-effectiveness also needs to be addressed in terms of the usefulness or value of what is being provided. The commodities available in Europe and the deficits or opportunities for using additional food resources may not exactly match. Some of these questions of cost-effectiveness, usefulness and flexibility are considered more fully later (pp. 288-292). First, there is the initial question of 'need' for and the potential value of food aid as a resource for humanitarian ends or development in Africa. This question is approached by posing three further questions: (I) What are the requirements for food aid, having regard to the special circumstances of sub-Saharan Africa? (2) How is food employed as a resource? (3) What does the historical record tell us about the extent to which the potential of food aid is likely to be realized?

\section{Africa's food aid requirements: structural or transitory?}

The experience of the last 2 years has underscored the considerable difficulties inherent in attempting to assess the need for food aid in sub-Saharan Africa. There is an underlying trend towards greater levels of food imports, particularly small grains, wheat and rice, as well as vegetable oils and dairy products. These growing deficits concentrated in certain categories of commodities are found throughout the region. Socio-economic analysis suggests that the long-term differences in level of import dependence are associated with urbanization and rates of economic growth (and therefore purchasing power). Acute balance of payments problems in most African countries make it difficult to finance these imports commercially out of export earnings. This has intensified controversy surrounding these trends in imports.

Some commentators suggest that the food import problem, the short-term increase in import dependence, is an almost unavoidable concomitant of socio-economic transformation. Others see these trends as a reflection of 'bad policies', the failure to provide proper incentives to domestic agricultural producers and overvaluation of exchange rates. Even those who would not wholly subscribe to the 'bad policy' thesis emphasize that there is considerable scope for improvement in policies. Some countries, just as those in East and South Asia have done, will move towards greater self-sufficiency in food. Greater self-sufficiency is the stated long-term objective of African governments (the Lagos Plan of Action). Do these trends and policy moves have implications for food aid policy?

The most widely accepted way of estimating the requirement for food aid is based on characterizing the food balance sheet for staples (i.e. cereals, root crops, tubers, etc.). First, economic or minimum nutritional criteria are used to determine 
the total 'demand' or requirements for food staples or cereals in a region or the total economy. An estimate of domestic supply including production and carry-over stocks is subtracted to obtain an estimate of the import requirement or gap. The level of commercial imports is then determined by some economic decision rule and the requirement for food aid is calculated as a residual by deducting commercial imports from the total import requirement. Clearly, the economic capacity of many countries, particularly in a crisis situation, to finance imports commercially is very limited. To use scarce foreign exchange for this purpose therefore implies a serious squeeze on other vital imports.

The long-term upward trend in food imports can be taken to imply that at least for the foreseeable future the need for food aid is unlikely to decrease. Some countries will succeed in becoming less dependent on food aid, if not on food imports generally, but many others will fail to do so. This means that the probability in terms of an actuarial risk is that more concessional financing of imports will be required, and should be taken into account in the planning of European food aid policy. The onus is on those who argue for only maintaining or reducing levels of food aid to ensure that alternative financial mechanisms exist to meet the unavoidable food import bill of low-income countries. The notion of actuarial risk provides a useful metaphor for the problem. Just as insurance companies do not know exactly who will be making claims, they nevertheless can anticipate that the level of claims over several years will be such that adequate resources must be set aside to meet these. Some of the projections made only 3 or 4 years ago for food aid requirements of sub-Saharan Africa in 1990 have already been exceeded in the crisis period of $1984-85$.

As recent events have shown, responding to the food aid requirements of sub-Saharan Africa poses a number of difficulties. The analysis of trends provides some idea of the overall dimension of the food aid requirement in the medium-term. However, year to year requirements for food aid are dominated by short-term transitory requirements. The high level of variability in agricultural production in the more drought-prone areas of Africa leads to large short-term differences between domestic production of food and annual consumption requirements. So over the last 12 months many countries have moved dramatically from requiring large-scale concessional imports to, in some cases, having exportable surpluses. As the weather patterns which influence food production are closely correlated through most of the drought-prone countries of Africa, this implies a sharp cyclical pattern to the level of overall import and food aid requirements. The relation between weather and agricultural production also imparts an asymmetry to the food problem. Drought, when sustained over several years, first reduces production but also gradually eats away food stocks and, through reduction in export earnings and general level of economic activity, weakens the economy. The favourable rainfall patterns lead to a dramatic upsurge in agricultural production. A lagged response by governments and donors to the drought can then create problems of excess supply. Governments that have been struggling to survive food crises are poorly placed to finance or provide the 
Table I. Sub-Saharan Africa: cereals food aid receipts by 'use' $1983^{-84}$ to $1984^{-85^{\circ}}$

\begin{tabular}{|c|c|c|c|c|c|c|c|}
\hline Year & $\begin{array}{l}\text { Programme/ } \\
\text { non- } \\
\text { project }\end{array}$ & $\begin{array}{l}\text { Agri- } \\
\text { cultural/ } \\
\text { rural } \\
\text { develop- } \\
\text { ments }\end{array}$ & Nutritional & Other & $\begin{array}{l}\text { Food } \\
\text { security } \\
\text { project }\end{array}$ & $\begin{array}{c}\text { Emergency } \\
\text { aid }\end{array}$ & Total \\
\hline $1983-84: 000$ tonnes & $x, 366$ & $43^{6}$ & 223 & 34 & 112 & 845 & $\begin{array}{r}3,016 \\
100\end{array}$ \\
\hline $1984-85: 000$ tonnes & $\begin{array}{r}45 \\
1,385\end{array}$ & $\begin{array}{r}14 \\
512\end{array}$ & $\begin{array}{r}7 \\
237\end{array}$ & $\begin{array}{r}1 \\
45\end{array}$ & $\begin{array}{r}4 \\
270\end{array}$ & $\begin{array}{r}25 \\
2,467\end{array}$ & 4,816 \\
\hline$\%$ total & 29 & 9 & 5 & 1 & 6 & 51 & 100 \\
\hline
\end{tabular}

-World Food Programme provisional unpublished data amended by author.

logistics and capacity to support large-scale rebuilding of stocks. There is a real danger that weather-induced fluctuations in production will be amplified by an agricultural policy cycle. For example, governments in Kenya, Malawi and Zimbabwe are finding it difficult, as surpluses build up, not to reduce real prices to growers and thereby run the risk of amplifying the downward effects on production of a return to drier conditions. The implications of the complex overall problems of agricultural production and import requirements for a more effective European response need to be considered in terms of the different forms in which food aid is provided.

\section{Forms and uses of food aid}

Emergency aid. Food aid is conventionally divided into emergency and development assistance (see Table $\mathrm{I}$ ). This distinction is useful insofar as it clearly links in with the transitory and structural elements in the food deficits of developing countries. Emergency aid is intended as a response to the abnormal circumstances of a natural or man-made crisis. The implication is that there are people who lack food or the resources to acquire food and so emergency provision of food provides an effective and direct response to their condition. Where food is readily available locally, i.e. within the region, this can be acquired and distributed. Otherwise imports of food into the region are required. These may come from elsewhere within the country, depending on logistical possibilities. Alternatively, imports may be required. The difficulties in the short term of acquiring and moving supplies within a country should not be underestimated. The logistical problems of bringing in food imports are more widely understood. These conditions are more likely to occur in a drought-caused food emergency than after an earthquake or a cyclone. Drought reduces agricultural production (not just food) and available food supplies shrink with the run down of stocks. The real incomes of self-provisioning peasant producers contract as well as those of agricultural commodity suppliers. The latter face locally administered prices or prices determined on world markets which are likely to be insensitive to changes in their 
production. The incomes of labourers and the service trades who depend on agriculturalists for a livelihood all contract. These are circumstances in which an increase in food supply, if rapidly brought about and effectively distributed, can have an important and dramatic effect in saving lives and preventing social disintegration of communities. Virtually everyone agrees, therefore, with the need for emergency aid. The issues are more those of ensuring appropriate and effective responses to problems as they arise.

On the evidence of $1984-85$ the potential need for emergency aid may go far beyond what was previously earmarked by the donors, including the EC, for these purposes. The commodities earmarked included commitment to provide food through the International Emergency Food Reserve, contributions to the World Food Programme emergency programme, and a reserve of commodities provisionally earmarked by the EC to meet as yet unspecified requests. Circumstances that require supplementary allocations inevitably imply delay and, as discussed below, reduce the effectiveness of emergency assistance.

Food aid for development. The idea of using food imports for promoting development raises more complex issues about the appropriate circumstances in which food aid should be provided (Clay \& Singer, 1985). 'Food aid' may of course take the form of financing local purchases of food, but this is really only a covert form of balance of payments support converting foreign currency to buy food. Are imports to be employed only where these meet part of a continuing deficit or should additional imports be provided? The generally accepted view, for example now written into the US legislation and part of the project appraisal requirements of the World Food Programme, is ambiguous. It is stressed that imports should not compete with domestic production to the detriment of local agricultural development. In essence, therefore, the distinction between emergency and developmental assistance is between the supposedly more rapid response to an unanticipated requirement and an action that is part of a pre-prepared design, even if the actual amounts provided vary from year to year. The distinction is one of planning and administrative practice. In looking for more effective European responses to African food problems the question should be how can these practices be improved?'.

Cutting across the distinction between emergency and developmental food aid is the critical question of uses and the economic implications for the recipient economy, and the people who are to be direct beneficiaries of aid. The conventional distinction is between 'programme', or non-project, food aid and various 'project' uses. The crisis year of $1984-85$ is exceptional. In most years non-project food aid represents the largest category of food aid to sub-Saharan Africa. It is provided by the EC and other donors directly to governments who sell commodities through their internal marketing system or provide rations or wages in kind to particular, and often relatively privileged, groups of the population. Clearly the sale of food to local markets raises questions about possible negative impact on domestic food production. This and other related effects are discussed (pp. 288-292).

A recent important development has been that of 'food security' projects where 
grain is channelled into government stocks under a long-term agreement. For practical economic purposes this too is programme assistance within a long-term agreement. Another important project use of food aid is for direct distribution to pre-identified groups of beneficiaries within a multi-year plan. Projects can include food-for-work. Important examples are the long-standing and relatively large rural works programmes in Ethiopia and the small nation of Lesotho. Overall, less than $10 \%$ of food aid to Africa is accounted for by 'agricultural and rural development uses of food aid' that have also included a complex range of uses apart from food-for-work. An example is the programme for financing restocking by nomadic households in the Turkana region in northern Kenya.

One major direct project use of food aid is in nutritional improvement programmes. These include those for vulnerable groups such as small children and nursing mothers as well as school feeding. These are again a relatively minor use of total food aid. Emergency aid involves the direct distribution of food to refugees in camps or to displaced persons. However, a substantial proportion of such emergency food also flows into government distribution systems as in effect unplanned, non-project food aid provided through a speedier channel of delivery. This is a serious issue; some countries (for example Mozambique) have continued to require emergency food aid year after year de facto on a regular basis.

The considerable controversy that surrounds the economic and social implications of food aid for recipient countries, and the proposals and attempts to improve the effectiveness of European food aid, relate to these different categories of assistance.

\section{The impact of food aid on recipient economy and agricultural development}

There are few areas in the development literature more controversial than that of the impact of food aid on the economy and particularly on the agriculture of recipient countries. Food aid has both its proponents and detractors who have identified potential positive ('incentive') and negative ('disincentive') effects on recipient economies. Much attention is given to direct disincentive effects resulting from food aid, and imports generally, by lowering prices for domestic producers. Such an impact may be only localized in the case of projects unless they are large in relation to the recipient economy, whereas programme aid and also large-scale emergency aid could have a potentially negative impact on the whole agricultural sector. These effects would be absent where there is a counteracting effect of higher levels of consumption of basic foodstuffs (most obviously in a period of acute scarcity) and through encouraging the long-term rate of growth in food consumption (by fostering economic growth). In order to understand when positive or negative effects are more likely to occur, it is necessary to take account of the potentially complex and different effects that food aid may have on a recipient economy.

Food aid can have a direct and easily perceived negative impact on producer prices and production in a recipient economy. But such a potential effect should not be considered in isolation from the impact on food consumption and the 
economy more generally. These interactions are most readily understood in terms of the two extremes or 'boundary' cases where food aid either represents additional food imports or replaces commercial purchases.

Additional food imports. The potential negative effect through prices on domestic food production and the countervailing positive effect of food aid are greatest with the introduction of food aid which is wholly additional to any imports that would have occurred otherwise. The additional imports would have a depressive effect on domestic prices and production. However, such a reduction in prices would also have a (partially or wholly) compensating positive effect on demand. Lower prices encourage more food consumption and this may be a highly desirable effect, for example in a period of acute food shortage. This consumption or demand-side effect will be maximized where the government intervenes to segment the market and targets food subsidies (or in the extreme case provides food free) to low-income households. The extreme case would be ration distribution to refugees or displaced people with effectively little or no purchasing power.

The other important effect of providing governments with additional food is the revenue or counterpart funds generated by local sales. Such budgetary support is fungible, that is available for any purpose, developmental or otherwise. Such aid could relieve otherwise unsustainable budgetary pressures on a government with little scope for increasing domestic taxation in the short run. But reliance on concessionary food imports may have disincentive 'complacency' effects by reducing the priority which governments accord to agricultural development. Alternatively, as suggested, the revenue from sales can provide the sources for investments in agriculture. Food aid could promote long-term economic growth by reducing real wage costs or encourage 'unproductive' tertiary sector growth and accelerated urbanization. There is also danger of 'fiscal dependence' of recipient governments on the sale of aid commodities (Clay, I979; Cathie, 1982). Clearly the policy framework within which food aid is provided by the donor and employed by the recipient government is the crucial variable. Donors have therefore sought to obtain commitments and tried to monitor the actual uses of such revenue by the establishment of special accounts for counterpart funds.

Food aid for balance of payments support. Alternatively food aid can replace commercial imports and thereby provide balance of payments support. There will not be a direct disincentive effect through prices because there is no effect on overall food supply. Such balance of payments support can have an important and positive impact on a country's overall development effort, freeing scarce foreign exchange for other critical imports such as spare parts, petroleum and of course agricultural inputs especially in the current period of general economic difficulty in Africa. But balance of payments support can have complacency effects on policy both with regard to avoiding adjustment in exchange rates and reducing the financial and political pressures to invest in domestic food production capability.

Much of the opposition to food aid being explicitly used as balance of payments support and thereby militating against the proper planning of such aid, has been 
from agricultural interests. The EC Council of Ministers explicitly rejected the objective of a balance of payments support put forward in the EC Commission ( $1983 a$ ) discussion paper on food aid, yet a large proportion of food aid imports is being channelled into urban food systems in Africa. The underlying rationale is that this aid is intended to reduce the burden of imports, providing balance of payments support.

Additional food or balance of payments support? Analysts and commentators of left and right are antipathetic to food aid. Those in the middle tend to prefer its use for balance of payments support. Official donor policy favours additionality. At least the range of possible positive and negative effects of bulk food aid indicates why issues of policy and economic management must be of central concern.

Other effects. Food aid may bring about long-term changes in consumer tastes creating dependence on imports, and the technological basis of import dependence has also been widely stressed. On the positive side relatively lower food prices, depending on targetting, can have a positive long-term employment effect through lowering the level of wages and thereby possibly favouring labour-intensive production throughout the economy. This could be especially so in the case of labour-intensive rural works. The distribution of benefits in terms of lower food prices might favour urban consumers at the expense of small-scale rural producers or, alternatively, favour poor or crisis-affected households in a period of food deficit. All these potentially contradictory effects concern prices and the specific forms of interventions in agricultural markets by recipient governments.

Confronted with such a range of possibilities some protagonists have nevertheless felt able to conclude that on balance the impact of food aid is negative. Others, including the author, while recognizing unquestionably negative experiences, would agree with Stevens (1979), that food aid is like a curate's egg, 'good in parts'. The long continued debate even about the impact of food aid on specific countries, for example, Bangladesh, Egypt, India and Sri Lanka, which have been recipients of food aid over many decades, suggests that for analytical reasons the outcome is intrinsically indeterminate. The implication drawn, for example by Mellor (1982) and Singer (1978), is that food aid offers opportunities, but realization depends on constructive policies on the part of recipients and donors.

Whatever the historical record in Asia or Latin America, it is legitimate to ask what is the relevance of this experience for sub-Saharan Africa. Very few African countries have been receiving food aid on a significant scale over an extended period of time. The level of cereals food aid to sub-Saharan Africa rose from quite insignificant levels 20 years ago to around I million tonnes concentrated on drought-affected countries in $1974-75$ and $1975-76$. Subsequently there was a sharp decline followed by a steady increase in levels of cereals food aid to around $2 \frac{1}{2}$ million tonnes in the early 1980 s. In the crisis year, $1984-85$, total tonnage reached 5 million and at least fifteen countries received over 100000 tonnes each.

There are prima facie reasons for believing that in Africa the risks of disincentives are higher and the incentive effects more difficult to achieve than 
amongst the first generation of food aid recipients such as Brazil, India and South Korea. First, the opportunities for industrial growth have been more restricted since the late 1970 s and few African countries are well placed to benefit from those opportunities which exist. Second, the high proportion of emergency, in effect unplanned non-project food aid, in the total of food aid suggests that to date there has been less systematic planning than in Asia, both on the part of recipient countries and donors. Third, the scope for labour-intensive rural works is, with the very important exception of Ethiopia, considerably less in sub-Saharan Africa. Populations are more thinly spread, and there is no long-standing tradition of organizing such works as in South Asia. Where the colonial authorities engaged in forced labour, this is felt to have left a tradition of hostility to food-for-work, for example, in the former Portuguese colonies. Lastly, the commodity composition of food aid, dominated by wheat and rice, is poorly matched to the consumption requirements of the majority of sub-Saharan countries. Where cereals predominate in diets then, with a few important exceptions, maize, sorghum and millets are the predominate staples. In some central and southern African countries, roots and tubers are a significant proportion of the diet, particularly in rural areas. The growth of imports to feed the towns may result in a de-linking of urban consumption from the rural hinterland. Investments in logistics, when concentrated on port facilities and the distribution system in the cities, may reduce the cost of imports relative to domestic marketed output. The question may be posed thus: to what extent do specific patterns of investment in the food processing and food distribution systems make the apparent response of domestic supply to commercial incentives lower than it could be otherwise?

The debate on the past experience with food aid largely outside of Africa is relevant only insofar as it provides pointers to policy in the context of the present and likely realities in sub-Saharan Africa. There is likely to be a continuing but difficult-to-predict demand for large-scale emergency assistance. The scale of this demand will be sensitive to large-scale 'disaster preparedness' and food security measures. Most countries have already built up substantial deficits of certain categories of foods, notably wheat, rice, vegetable oils and dairy products. The need to respond more effectively to emergency needs is generally accepted. Pragmatically, the question of whether large-scale food aid should continue to be provided for development purposes in the context of existing and growing structural deficits must depend on whether it can be used effectively to support long-term development.

The possibilities for using food aid are constrained by the resources and management capacity of both donor agency and recipient governments and the wider political economic environment. If food aid is an extra resource, and the evidence is that there are resources available that would not otherwise be on offer in the absence of food surpluses, then clearly there are real challenges for policy and programme management. Before turning to these possibilities, it is important again to recognize the constraints that may be implicit in the opportunity. The argument here is that food aid is a potentially valuable resource, but a difficult 
resource to handle, so that considerable skill and flexibility are required in using it effectively. It would be a pity if the agricultural policy underpinning food aid were to impose constraints that prevent effective developmental humanitarian use of these resources. Again, the recent US Food Security Act provides an example. It is not enough that US food assistance programmes should utilize US surplus commodities. The legislation has now proceeded to mandate minimum quantities of particular commodities which are in surplus, such as skimmed milk powder. Such mandates are buttressing domestic agricultural interests without regard to the restrictions they place on the effectiveness of the US food aid programme. In examining the EC programme it is important to ask whether there is greater flexibility, and scope for yet greater flexibility, than is seen elsewhere.

\section{Things that could be done}

Anyone making suggestions for improvement or reform of EC procedures must recognize that this is a difficult, politically complicated task. There are three institutionalized foci of political negotiation within the EC: the European Parliament, the Commission, and the Council of Ministers. There is no coherent unified position within any of these institutions. Nevertheless, the enormity of the problems which have been exposed yet again in the recent crisis in Africa and the less than satisfactory performance of the EC require that things must be improved. This is a long-term task and suggestions for improvement ought to have regard to what might be more readily achieved in terms of improvements in administrative practice and in political decision processes.

Emergency food aid. The core of the problem is that the EC is ill-equipped to act quickly in the immediate post-disaster stage of a crisis. NGOs and some smaller bilateral programmes can respond more promptly. The EC procedures make it likely that there can be a larger but lagged response. But the whole experience of emergency food aid is that late responses run the risk of doing greater harm in terms of subsequent disincentive problems. As a crude rule of thumb, every tonne delivered at the immediate post-disaster stage in a properly packaged form is worth 3 or 4 tonnes delivered 6-9 months later. The issues therefore are how can the EC respond more quickly and with more appropriate resources?

The question of response needs to be considered in relation to the different ways in which food aid is provided. The EC Commission may provide aid directly to a recipient-country government. It may act indirectly either by providing commodities through NGOs or again indirectly in providing assistance as requested through the International Emergency Food Reserve. Questions about the rapid response must be related to the channel for assistance and an assessment of the possible flow of commodities through these channels.

The International Emergency Food Reserve is easiest to deal with since the EC is making commitments in advance of commodities that will be drawn on during the forthcoming year. It is operationally feasible to think of earmarking specific commodities that are then ready for immediate or early dispatch in meeting such commitments. The obstacles to doing so are those of increased cost and of finding 
purchasing, processing, packaging and storage procedures which are acceptable to the agricultural interests within the EC. The argument that rapidly available commodities have a considerably higher value in an emergency situation suggests that higher cost ought not to be an obstacle in this case. The procedures for mobilization are frankly more concerned with an overall balance or equity amongst the EC's national agricultural ministries and boards and their farming and agribusiness clients. If requirements can be anticipated in advance then even if procedures that reflect these realities are to be followed, there is, in principle, no problem of going through the procedures and placing purchased commodities in an operational reserve of commodities which are ready for early or immediate shipment.*

The requirements of NGOs for emergency commodities are likely to be relatively small in most years. A step forward would be some advanced planning of the level of commodities and types of commodities, including details of packaging, that might be required for NGO programmes. Again, there are real costs associated with such advance planning, but it is possible. The onus to promote such working procedures is as much on the NGOs as on the EC Commission and, indeed, national governments. Historically, it is worth recalling that unlike the North American agencies, many EC NGOs have been reluctant to engage in such pre-planning, lest it prejudice their margin of manoeuvre vis-ä-vis national and EC bureaucracies and political institutions. It is naive to assume that bureaucratic procedures will automatically work and that resources will be available whenever they are required. This is one of the lessons of the last 18 months. Perhaps those who complained were less surprised than they appeared. If NGOs see a role for themselves in the provision of emergency food aid, then they must work to establish procedures that ensure that resources are available when they are urgently needed.

The argument in the case of both these channels is that an operational reserve or working stock of commodities is required, readily available for emergency action. The evidence of the recent past is that any such reserves must be larger than anything held in the past. None of this would be surprising to a commercial organization involved in international trade, wholesaling or retailing. Working stocks are an essential element of efficient operations. The awful reality is that international emergency procedures, which are costly anyway to organize, intended to save human life, mitigate or prevent suffering, are apparently not an appropriate area to organize in this way. The arguments of political difficulty and excessive cost are indefensible.

The area of direct EC or national government action in providing aid to recipient governments is more complicated. Commodities are provided on an emergency basis, which in effect means a speeded procedure without any of the preplanning and appraisal that should be undertaken in providing development

-A recent review by the Food and Agriculture Organization (1986) of prepositioned stocks suggests that overall response time by the EC could be reduced from an average of 4 months to $5^{-6}$ weeks for emergency shipments if the EC Commission controlled stocks held in European ports. 
assistance. This is a grey area. Part of such emergency assistance is virtually identical to that provided through indirect channels as already discussed. However, this channel is also used to cope with requests for assistance that could not be fitted into the normal procedures for programme aid. In the past this has sometimes included requests which simply came through too late. Other cases result from chronic problems of countries that are handling their food systems on a day to day crisis management basis. In the serious emergency case there is the need for advanced planning if commodities are' to be not merely committed quickly but also shipped promptly. Again, the availability of earmarked resources would undoubtedly facilitate early or immediate dispatch.

An 'operational' emergency food aid reserve. What would be the operational implications of the type of reserve or working stocks implied by this analysis of the emergency programmes? It implies a prepared plan for the direct purchase or earmarking of commodities held in intervention stocks. As with all working stocks these need only be held on a temporary basis and can be subsequently programmed through normal procedures. There are partial precedents for such commodity management within food aid programmes in the way other donors earmark commodities in advance to ensure their availability. The preplanning would require not merely notional totals of 'commodities' but much more careful working out of processing and even packaging commodities. This will of course be more costly and make heavier demands on management than existing practice.

The introduction of more planning into emergency responses also raises real difficulties in terms of ensuring an appropriate basket of readily available commodities. In an immediate post-disaster situation there is a need for prepackaged commodities in small quantities. These are costly to produce and store. In the next 'relief phase' of an emergency, requirements need to become sensitized to the normal food consumption patterns of the groups concerned. Different commodities are required, for example, to meet the needs of refugees in South-east Asia, South Asia and much of Africa. Some of these commodities are not available within the EC, notably white maize. In the case of other commodities, local purchases or a Third World export source, e.g. Thai rice, may be more appropriate. Such a reserve may need earmarked supplies of white maize.

The build up of the more ambitious programme of working stocks for emergency purposes raises many administrative difficulties. It implies a greater investment in management and this is precisely where the EC Commission is poorly placed and many national aid agencies are now in a weaker position because of cost cutting since the late 1970s. If strengthening the management of the EC Commission programme can only be achieved in the context of increasing the overall bureaucratic establishment in Brussels or the size of Directorate General viii (Development) as a whole, then there can be little prospect of improvement in the near future. This suggests the need for alternative innovative solutions outside the 'staff and line' structure of the Commission.

Emergency aid makes heavy demands for complementary resources in terms of management, logistics and personnel in the field. In this respect the EC 
Commission and most member governments are not well placed. NGOs are better placed to provide and organize personnel for field action and they may also be able to handle logistics of at least small-scale assistance more effectively. International organizations are better placed in building up an international network of management logistics and local capacity to move commodities on a large scale. Overall, a combination of more effective preplanning, provision of earmarked commodities on the EC side, use of international channels such as the World Food Programme and the International Emergency Food Reserve, has in the long run the best prospects for becoming the most effective mechanism for large-scale emergency assistance.

A more effective resource for development. The greater part of food aid to Africa has been programme, or non-project, food aid. Programme food aid ought to be clearly distinguished in terms of the intended direct effect of the resource transfer: to provide balance of payments support to the recipient government or to place additional food in its hands for distribution and consequent generation of revenue. The discussion of the developmental effectiveness of programme food aid therefore needs to be related to these distinct intentions.

Food aid for balance of payments support is fungible, that is it can be used for virtually any purpose. The effectiveness of such assistance ought to be considered in terms of the short-term impact and the likely long-term implications. Fungibility implies that a clear economic policy framework for the short-term is crucial. The linking of such assistance to a Structural Adjustment Loan by the World Bank or an International Monetary Fund Standby Agreement can provide such a planned framework. The presumption is that there is a deficit in food in the short run that government will be obliged to meet anyway. The short-term assistance frees foreign exchange in a difficult set of economic circumstances for other crucial imports or allows the government to reduce other borrowing or a reduction in reserves to meet imports. Balance of payments support has to be given with a careful regard to the long-term implications. Such resources should not be provided where these may discourage constructive restructuring of economic policy. This issue is illustrated by looking separately at the provision of aid in the form of dairy products and cereals.

Dairy food aid. World markets in dairy products are depressed by large surpluses. Most developed-country producers are dumping into developingcountry markets. Food aid has been used to facilitate the development of local dairy production as 'project food aid'. The most well-known example is Operation Flood but there are other such projects in Africa, for example Kenya and Tanzania. European Development Fund and bilateral European aid has also been used to support dairy development through complementary investment and technical cooperation.

With fluctuating local supply, local dairy production capacity typically depends for at least a proportion of its inputs on imported dairy products for reconstitution. Food aid can therefore facilitate the development of local production through financing such imports but attention has always focused on the local generation of 
revenue. Either the revenue from the sale by government to the dairy industry or revenue going to the dairy industry from sale of final products, depending on accounting practice, provides counterpart funds. These funds can be used to support local dairy development or subsidize the local processing capacity. With markets overhung by surpluses, the locally reconstituted commercially imported dairy products may be unable to compete with imported full-cream milk powder. What is at issue is not just the prices at which domestic producers can be encouraged to supply milk but also the operating costs of a local processing industry. Are local prices to final consumers set at a level which will ultimately allow the profitable expansion of local dairy production? In present market circumstances tariffs or other forms of restriction on commercial imports of products in a form readily saleable to the final consumer may be required. The real danger is that food aid will be used to subsidize both the consumer and local processing capacity by making possible, sales of locally reprocessed commodities at import price levels, established by dumping, or even below these levels where exchange rates are overvalued. Dairy aid is meeting balance of payments costs of providing raw materials to a local industry. Consumers are being subsidized, but are these desirable beneficiary groups or middle and upper income urban consumers? Is the aid being provided in a context within which a local production capacity will develop that can be based on local milk production? Alternatively, are there serious prospects that the country will be able to afford and can economically justify commercial imports?

Cereals food aid. Cereals aid is typically provided to meet part of an 'import gap' identified by the government itself or by the Food and Agriculture Organization Global Information and Early Warning System. That system is moving towards distinguishing between structural or long-term deficit and a shortfall resulting from an emergency such as drought. But what is this 'structural' deficit in a commodity such as wheat or rice which may not be produced locally? Critics of food aid blame imports for developing tastes or at least encouraging trends which began during the colonial period. But the size of a structural deficit in such a commodity, at least in the long run, is a function of prices to the consumer, investments in storage, processing and promotion of products as well as the general economic situation. Urbanization and economic growth increase the demand for convenience foods as does the lifestyle of single male migrants and the high energy costs of food preparation.

Traditionally food aid has been provided in terms of the food deficit as it is now, with little regard for the long-term food policies that are being indirectly promoted. A long-term 'food strategy' ought to provide the framework for food aid planning. Historically, aid agencies have handled on a year by year basis the level of food aid that was expected to be available in relation to year by year requests from recipient countries. This pattern of food-aid programming reflected the origins of food aid in agricultural surpluses and the uncertainties associated with levels of available commodities. An encouraging development has been the growing emphasis on multi-year programming and links to a food policy or food security plan on the part 
of the recipient. Both sustained advocacy from outside and pressure from within the aid bureaucracies is needed to make this a reality. Agricultural interests have always been unenthusiastic about linking more than a small proportion of food aid to such long-term agreements. Treasuries also dislike the development of long-term commitments in a programme which is financed by annual allocations in contrast to investment credits or grants.

Where food aid is intended to provide additional food imports there are, as already suggested, real and immediate dangers of disincentive effects. These effects are likely to be most severe when commodities are sold on local markets. In a crisis situation this may be be justified because without intervention people could starve at 'market clearing prices' and be forced to sell their assets and abandon their livelihoods. The seriousness of this issue underscores the importance of restricting emergency aid to genuinely acute emergency situations rather than chronic problems faced by governments in managing their food systems.

The reduction in disincentive effects and increase in consumption that may be achieved by a partition of food markets suggests that aid can be provided to support constructive interventions. But the issue turns on whether or not partitioning targets food subsidies and free food on to the poorest households. This will maximize the increase in consumption and improve the nutritional status of the population. In looking at the experience of food aid in Africa, and food policy more generally in that continent, it is clear that much more needs to be done to understand and examine the effects of government food system interventions. For example, in Egypt cheap bread policies have brought significant support to the real incomes of poor consumers and measurable nutritional benefits side by side with disincentives to wheat production.

The case for linking food aid to a 'food strategy' has been based on recognition by, for example, the EC Commission (1982), of such policy issues. First, there is general agreement that food aid ought to be linked to a constructive food policy both for handling an immediate gap and for promoting long-term development. The notion of a food strategy as it has evolved from discussions first in the World Food Council in the late 1970 s and later promoted in the EC by the former Commissioner, M. Pisani, has more specific implications. The food strategy emphasizes a number of key linkages. First, there is a presumption that food aid is to be integrated in a framework for long-term self-reliance in food. Many have argued that either the balance of payments support from food aid or counterpart funds from sales, or indeed revenues from sales whatever the direct impact of food aid, ought to be linked to investments in local food production. Food aid should be provided to make food aid and food imports unnecessary. A problem with this view is that it ignores questions of 'comparative advantage' at the individual country level. The long experience of India illustrates this dilemma.

During the I950s and I 960 s food aid to India was used to support a cheap food policy. The evidence is that food consumption was higher than it would have been otherwise whilst domestic cereal production was somewhat reduced. But cheaper food kept down the level of wages. This in turn favoured economic growth and 
increased the domestic demand for other agricultural commodities. Land did not lie idle and was used to produce agricultural raw materials and the balance of relative prices favoured oil seed and pulse production. Econometric research suggests that the overall effect was possibly reduced cereal production but higher agricultural production than would have occurred in the absence of cheap imported food. Subsequently, India has switched to incentive prices for wheat producers, promoted the spread of green revolution technology and ended cereals food aid. India now has a wheat surplus but, with land switching into cereals from other crops, a different problem is created by 'supply imbalances' of vegetable oil and pulses. The less favourable international economic environment and less well-developed intersectoral economic linkages may make it less likely that African countries can now follow the Indian example of the r950s and I960s. Circumstances may favour a push to self-reliance in food. However, world markets will make it very difficult for any surpluses from fluctuating production to be disposed of through exports in contrast to traditional agricultural export commodities. This is why the current build up of maize surpluses in Kenya, Malawi and Zimbabwe pose agricultural policy problems more severe than fluctuations in cotton, tea or tobacco production.

Food aid from any one source is filling only part of the immediate food gap. Better planning of food aid therefore implies the linking of Community Action and National Action to the food aid provided by the other donors. An emphasis on a bilateral relationship is unhelpful in planning how to meet the import gap as well as the use of freed foreign exchange counterpart funds.

The EC Commission emphasizes the positive linkage between food aid and other aid through the European Development Fund or bilateral EC member state supported projects. Counterpart funds from the sale of food aid could be used to meet the local costs of these projects (EC Commission, 1983a). But attempts at such bilateral carving up of government revenue raises questions about efficient resource allocation. The alternative is consultation and co-operation amongst the donors with a recipient government on establishing a common counterpart fund for all such revenues from food aid. Such a fund makes it easier to link food aid to constructive economic policies for the whole economy as well as for agriculture.

Such discussions raise questions about the conditions under which food aid will be provided. There is evidence, for example in negotiations for the Third Lome Convention, that developing countries are unhappy about conditionality. Some developing countries who are signatories to the convention see this as an infringement of national sovereignty. Other commentators, perhaps more cogently, argue that donors may lack a coherent sense of what ought to be done at the country level. Yet the alternative to common counterpart funds, closer consultation between government and donors and co-ordination of food aid flows is unattractive. A sequence of bilateral negotiations by governments with individual donors has had disastrous results in the provision of emergency aid (for example, Sudan) and looks like an unsatisfactory formula for developmental assistance. Perhaps co-ordination of physical flows, the actual shipments, to avoid bottlenecks 
and distribution difficulties is the most useful and uncontentious starting point for consultation on food aid.

The food strategy initiative by the EC and other bilateral donors underscores another problem of food aid. The EC Commission attempted to programme food aid within a wider framework of policies and other EC aid, initially in four countries: Kenya, Mali, Rwanda and Zambia (Lipton \& Heald, 1984; Royal Tropical Institute, 1984). Some of these experiences suggest that improvements in food aid programming and the development of an effective food strategy will be a slow affair. In Mali there was already a multi donor food strategy agreement into which the EC food strategy could be linked. Subsequently the level of emergency food aid has gone way beyond anything anticipated in that agreement. Food policy in Kenya too has been affected by a period of drought, and there were subsequent commercial imports and food aid on an unprecedented scale. Now there are at least temporary food surpluses available for export. After discussion a food strategy agreement was concluded by Zambia with the World Bank. This agreement now provides an important element in any framework for food-aid planning. These examples show how the economic policy framework of food aid allocation on an annual basis changes quite rapidly. A picture emerges of two steps forward, one step backwards, complicated by relationships with other major aid donors. It would be a pity if disappointments engendered by perhaps initially excessive expectations of a special EC role to a retreat on food strategies. A problem for food aid policy, and perhaps policy more generally, is that of lack of 'staying power' on the donor side. Food strategies no longer look quite so fashionable and the temptation is to focus scarce aid agency planning and management resources on some other topical initiatives.

Another important lesson of recent events has been the need for donor flexibility. Suddenly, the need for food aid to Africa appeared to double almost overnight and then just as quickly these anticipated deficits have shrunk or turned into exportable surpluses. Current circumstances offer temporary opportunities for initiatives that could encourage food production in Africa and if not prevent, at least reduce, the scale of the next down-swing. For example, a commodity swap agreement such as that which Australia has negotiated with Zimbabwe, providing wheat which is in deficit in exchange for maize to be exported as food aid elsewhere in the region, reduces the short-run costs of surplus production and encourages the development of food trade linkages within Africa. The EC has been also looking into the possibility of financing the build up of food security stocks in southern Africa with locally purchased grain. Unlike the swap agreement this is no longer conventional food aid. But an appropriate response has also to be prompt. Reductions in prices forced by the build up of local stocks or the sale on local markets of delayed food aid shipments increases the danger of building a policy cycle on to the fluctuations caused by the weather. The rapidly changing food situation in Africa intensifies the difficulties of food-aid programming as well as local food security policy. Does the EC have the flexibility to respond quickly? At some moments large-scale aid is needed to cope with transitory difficulties. Suddenly the situation shifts to one of 
surpluses where triangular transactions, buying food in Africa on local purchase to support projects that otherwise would be supplied by food (aid) imports, would be more beneficial.

The Campaign Against World Hunger provision that allows substitution of non-food assistance for food aid already sanctioned with the EC programme ought to have an important role in these circumstances (EC Commission, $1983 b$ ). How is this provision being employed? For long-term food security in the region, stocks built up from local grain and imported cereals may have a more important role in such a volatile situation. There has been bad experience with such reserves in the past and they are costly. But is there a practical alternative to the combination of developing an international capacity to respond flexibly and quickly on a large scale and improving food security in the region? Are the EC structures in their present form capable of exploiting that difficult opportunity? If not, then in this European context, surely the issue is one of working towards a restructuring of these institutions.

\section{Postscript}

The EC adopted in December 1986, during the period of the British Presidency of Council, a new management regulation for food aid providing for more 'flexibility' in buying food in the Third World, delegating more responsibility to the officials administering aid and allowing aid to build up food-security stocks in developing countries.

\section{REFERENCES}

Cathie, J. (1982). The Political Economy of Food Aid. Aldershot: Gower.

Clay, E. J. (1979). Food Policy 4, (2), I 29-1 33.

Clay, E. J. \& Singer, H. W. (1985). Food Aid and Development: Issues and Evidence, Occasional Papers no. 3. Rome: World Food Programme.

European Communities Commission (I982). Food Strategies: a New Form of Cooperation between Europe and the Countries of the Third World, Europe Information (Development) $\mathrm{DE}_{40}\left(\mathrm{X}_{374} / 82\right)$. Brussels: EEC.

European Communities Commission (1983a). Food Aid for Development, COM (83) 141 final. Brussels: EEC.

European Communities Commission $(1983 b)$. Council Regulation (EEC) no. $1993 / 83$ of 13 July 1983, Official Journal of the European Communities 26, 20 July, Lig6.

Food and Agriculture Organization (1986). Committee on Food Security document no. 86/5. Rome: FAO.

Lipton, M. \& Heald, C. (1984). Commissioned Study no. 6. University of Sussex: Institute of Development Studies.

Mellor, J. W. (1982). American fournal of Agricultural Economics 64, (2), 304-31 I.

Royal Tropical Institute (1984). Food Strategies in Four African Countries: Food Policy Formation in Kenya, Mali, Rwanda, Zambia. Amsterdam: Royal Tropical Institute.

Singer, H. W. (1978). Food Aid Policies and Programmes: A Survey of Studies of Food Aid, WFP/CFA 5/5-C. Rome: World Food Programme.

Stevens, C. (1979). Food Aid and the Developing World. London: Crom Helm. 